\section{RMD Open}

Rheumatic \&

Musculoskeletal Diseases

To cite: Bultink IEM, Lems WF. Systemic lupus erythematosus and fractures. RMD Open 2015;1:e000069. doi:10.1136/rmdopen-2015000069

- Prepublication history for this paper is available online. To view these files please visit the journal online (http://dx.doi.org/10.1136/ rmdopen-2015-000069)

Received 12 January 2015 Revised 14 February 2015 Accepted 22 February 2015

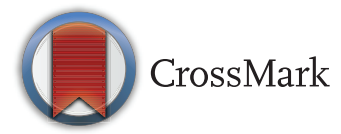

Department of

Rheumatology, Amsterdam Rheumatology and Immunology Center, vU University Medical Center, Amsterdam, The Netherlands

Correspondence to Dr Irene E M Bultink; iem.bultink@vumc.nl

\title{
Systemic lupus erythematosus and fractures
}

\author{
Irene E M Bultink, Willem F Lems
}

\section{ABSTRACT}

Since survival of patients with systemic lupus erythematosus (SLE) has improved over the past decades, increasing attention is focused on complications of the disease. Osteoporosis and fractures contribute to damage in the second most frequently involved organ system in SLE: the musculoskeletal system. Recent studies have reported a high frequency of reduced bone mineral density in SLE, and an increased risk of peripheral and vertebral fractures. The incidence of symptomatic fractures is increased 1.2-4.7-fold in patients with SLE. A large population-based study on 4343 patients with SLE and 21780 age-matched and sex-matched controls, demonstrated previous glucocorticoid use and longer disease duration as important risk factors for symptomatic fractures in SLE. Prevalent vertebral fractures are demonstrated in $18-50 \%$ of these relatively young patients, and one in three of these patients has normal bone density.

The aetiology of bone loss in SLE is supposed to be multifactorial, involving clinical osteoporosis risk factors, systemic inflammation, serological factors, metabolic factors, hormonal factors, medicationinduced adverse effects and, possibly, genetic factors. A 6-year follow-up study on Dutch patients with SLE revealed that low 25-hydroxyvitamin D serum levels, low body mass index and baseline use of antimalarials were associated with bone loss. In addition, a dose-dependent relationship between glucocorticoid use and bone loss was demonstrated in longitudinal studies in SLE. These findings have implications for daily clinical practice, because vitamin $D$ insufficiency is highly frequent in SLE, antimalarials are regarded as 'anchor drugs' for therapy and the majority of patients with SLE are on chronic glucocorticoid treatment.

\section{INTRODUCTION}

During the Osteorheumatology International Congress in October 2014 in Genoa, Italy, attention was paid to fracture risk in inflammatory rheumatic diseases. This review discusses the epidemiology and aetiology of (peripheral and vertebral) fractures in patients with systemic lupus erythematosus (SLE), and provides a summary of factors contributing to the increased bone loss in SLE.

\section{FRACTURES IN SLE}

\section{Epidemiology and aetiology of symptomatic}

\section{fractures}

In recent years, a large number of studies on the increased risk of osteoporosis and the associated risk factors in patients with SLE have been published. In contrast, the number of studies on fractures in SLE is relatively limited.

Symptomatic fractures have been reported in $6-42 \%$ of patients since lupus diagnosis, ${ }^{1-8}$ and the hip, vertebra, ankle, rib, foot and arm are the most frequent sites of frac-

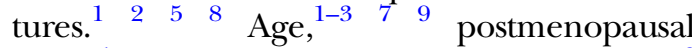
status, ${ }^{1}$ non-African-American ethnicity, ${ }^{6}$ smoking, ${ }^{6}$ alcohol intake, ${ }^{10}$ obesity, ${ }^{6}$ reduced bone mineral density (BMD), ${ }^{3} 8$ disease duration, ${ }^{5}{ }^{11}$ renal insufficiency, ${ }^{6}$ comorbidity, ${ }^{7}$ presence of lupus anticoagulant ${ }^{6}$ and Raynaud's syndrome, ${ }^{6}$ are reported as risk factors for symptomatic fractures in SLE. In addition, duration of glucocorticoid (GC) treatment, ${ }^{2} 78$ recent GC therapy, ${ }^{11}$ cumulative and high-dose GC use, ${ }^{1}{ }^{12}$ and pulse steroid therapy ever, ${ }^{6}$ are predictors of symptomatic fractures in patients with lupus. Moreover, ever use of intravenous cyclophosphamide was a predictor for femoral neck fractures in patients with lupus in Taiwan. ${ }^{9}$

The majority of data on fractures in SLE were reported from cohort studies while only a few population-based studies on all symptomatic fractures in SLE have been performed (table 1). ${ }^{2} 71011$

Three of these studies were performed in populations from specialised lupus centres in university hospitals and reported a 1.84.7-fold increased incidence of symptomatic fractures in (predominantly female) patients with SLE compared with healthy agematched and sex-matched controls. ${ }^{2}{ }^{2} 10$ 
Table 1 Population-based studies on all symptomatic fractures in patients with systemic lupus erythematosus

\begin{tabular}{|c|c|c|c|c|c|c|c|c|}
\hline Authors & Country & Setting & $\begin{array}{l}\text { Number of } \\
\text { patients }\end{array}$ & $\begin{array}{l}\text { Female } \\
\text { gender } \\
(\%)\end{array}$ & $\begin{array}{l}\text { Mean } \\
\text { age } \\
\text { (years) }\end{array}$ & $\begin{array}{l}\text { Follow-up } \\
\text { duration } \\
\text { (years) }\end{array}$ & $\begin{array}{l}\text { Relative } \\
\text { risk }\end{array}$ & Risk factors \\
\hline $\begin{array}{l}\text { Ramsey-Goldman } \\
\text { et af }\end{array}$ & USA & $\begin{array}{l}\text { University } \\
\text { hospital }\end{array}$ & 702 & 100 & 45.4 & 8.2 & 4.7 & $\begin{array}{l}\text { Older age at lupus } \\
\text { diagnosis } \\
\text { Duration GC use }\end{array}$ \\
\hline Rhew et $a l^{10}$ & USA & $\begin{array}{l}\text { University } \\
\text { hospital }\end{array}$ & 100 & 100 & 44.1 & 2 & 3.3 & Alcohol use \\
\hline Bultink et $a l^{11}$ & UK & $\begin{array}{l}\text { General } \\
\text { practitioners } \\
\text { database } \\
\text { (CPRD) }\end{array}$ & 4.343 & 89 & 46.7 & 6.4 & 1.22 & $\begin{array}{l}\text { GC use in previous } \\
6 \text { months } \\
\text { Disease duration } \\
\text { Seizures } \\
\text { Cerebrovascular } \\
\text { event Previous } \\
\text { fracture }\end{array}$ \\
\hline $\begin{array}{l}\text { Ekblom-Kullberg } \\
\text { et al }\end{array}$ & Finland & $\begin{array}{l}\text { University } \\
\text { hospital }\end{array}$ & $\begin{array}{l}222(204 \\
\text { women) }\end{array}$ & 92 & 47 & 13.1 & 1.8 (females) & $\begin{array}{l}\text { Age } \\
\text { Duration } \\
\text { GC use } \\
\text { Comorbidity }\end{array}$ \\
\hline
\end{tabular}

CPRD, Clinical Practice Research Datalink; GC, glucocorticoids.

However, investigating fracture incidence in a tertiary referral centre is probably related to overestimating fracture occurrence due to the selection of patients with a more severe disease course. The largest populationbased study ${ }^{11}$ was performed in the UK and used data from the Clinical Practice Research Datalink, a general practitioner database. This study on 4343 patients with SLE and 21780 age-matched and sex-matched controls demonstrated a lower relative risk (RR 1.22, 95\% CI 1.05 to 1.42) of symptomatic fractures in patients with SLE compared to healthy subjects as reported in earlier studies. Fracture risk was further increased with longer disease duration and with GC use in the previous 6 months before fracture occurrence. Furthermore, three subgroups of patients with lupus at high risk of the occurrence of (subsequent) fractures were identified: patients with seizures or a past cerebrovascular event and patients with previous osteoporotic fractures. ${ }^{11}$ The increased fracture incidence in patients with seizures or a history of a cerebrovascular event might be explained by an increased risk of falls in these subgroups of patients and by the adverse effects of antiepileptic drugs on bone mass, and illustrates that fracture rate is particularly high in patients with severe SLE.

\section{Epidemiology and aetiology of prevalent vertebral fractures}

A case-control study on 136 patients with SLE from Sweden showed that the risk for symptomatic vertebral fractures was increased with an OR of 2.2. ${ }^{13}$

However, studies focusing only on symptomatic vertebral fractures might cause an underestimation of vertebral fracture occurrence, since studies in the general population $^{14}$ and in $\mathrm{SLE}^{48}$ have demonstrated that the majority of vertebral fractures do not come to clinical attention. Although morphometric vertebral fractures are often missed in daily practice, ${ }^{15}$ the identification of prevalent vertebral deformities is important, since these are associated with a reduction in quality of life, ${ }^{16}$ an increased risk of future fractures and an increased mortality risk in the general population. ${ }^{17}$

Seven cross-sectional studies ${ }^{4-23}$ and one longitudinal study ${ }^{8}$ on vertebral fractures, all using the standardised method of scoring vertebral deformities by Genant, ${ }^{24}$ showed the presence of at least one vertebral fracture in $18-50 \%$ of the patients with a mean age of 32-48 years (table 2 ).

Age, ${ }^{19-21}$ low BMD, ${ }^{18} 2021$ male sex, ${ }^{4}$ ever use of intravenous methylprednisolone, ${ }^{4}$ high body mass index ${ }^{20}$ and previous fractures, ${ }^{23}$ were associated with prevalent vertebral fractures. As expected, the majority (73-79\%) of fractures are grade 1 (20-25\% reduction of vertebral height) deformities and are localised in the thoracic spine. ${ }^{4}{ }^{18-23}$ In contrast to the high prevalence of vertebral fractures reported from cross-sectional studies, a recent 5-year prospective study on 127 female Chinese patients with SLE demonstrated a very low incidence (0.94 per 100 patient-years) of morphometric vertebral fractures. ${ }^{8}$ In that study, lumbar spine osteoporosis was identified as the most important predictor of incident vertebral fractures. Surprisingly, the majority (4 out of 7) of incident vertebral fractures detected in the study were classified as severe, grade III fractures $(>40 \%$ reduction in vertebral height), a finding that is in contrast with the predominantly mild (grade I) prevalent vertebral fractures reported from earlier cross-sectional studies. Therefore, the severity of the vertebral fractures found in the study by Zhu et al suggests inclusion of traumatic fractures. $^{25}$

According to the recent National Osteoporosis Foundation $(\mathrm{NOF})^{26}$ and the National Osteoporosis Guideline Group (NOGG) ${ }^{27}$ guidelines, the detection of 
Table 2 Studies on prevalent morphometric vertebral fractures in patients with systemic lupus erythematosus

\begin{tabular}{|c|c|c|c|c|c|c|}
\hline Authors & $\begin{array}{l}\text { Year of } \\
\text { publication }\end{array}$ & Country & $\begin{array}{l}\text { Number of } \\
\text { patients }\end{array}$ & $\begin{array}{l}\text { Mean age } \\
\text { (years) }\end{array}$ & $\begin{array}{l}\text { Percentage with } \geq 1 \\
\text { vertebral fracture }\end{array}$ & Risk factors \\
\hline Bultink et $a l^{4}$ & 2005 & $\begin{array}{l}\text { The } \\
\text { Netherlands }\end{array}$ & 90 & 41 & 20 & $\begin{array}{l}\text { Intravenous } \\
\text { methylprednisolone } \\
\text { Male gender }\end{array}$ \\
\hline Borba et al ${ }^{18}$ & 2005 & Brazil & 70 & 32 & 21.4 & $\begin{array}{l}\text { Low BMD } \\
\rightarrow \text { number } \\
\text { of fractures }\end{array}$ \\
\hline Mendoza-Pinto et $a l^{19}$ & 2009 & Mexico & 210 & 43 & 26.1 & $\begin{array}{l}\text { Age } \\
\text { Low hip BMD }\end{array}$ \\
\hline Li et $a$ PO $^{0}$ & 2009 & Hong Kong & 152 & 48 & 20.4 & $\begin{array}{l}\text { Age } \\
\text { High BMI } \\
\text { Low spine BMD }\end{array}$ \\
\hline Almehed et $a^{R^{1}}$ & 2010 & Sweden & 150 & 47 & 29 & $\begin{array}{l}\text { Age } \\
\text { Low hip BMD }\end{array}$ \\
\hline Garcia-Carrasco et a ${ }^{22}$ & 2011 & Mexico & 140 & 43 & 24.8 & NA \\
\hline Furukawa et $a^{p^{3}}$ & 2013 & Japan & 52 & 45 & 50 & Previous fractures \\
\hline Zhu et $a^{\beta}$ & 2014 & Hong Kong & 127 & 47 & 18.1 & NA \\
\hline
\end{tabular}

BMD, bone mineral density; BMI, body mass index; IV, intravenous; NA, not assessed.

one or more asymptomatic vertebral fractures in patients with a BMD in the osteopenic range is an indication for initiating antiosteoporotic agents. Therefore, the assessment of vertebral fractures in addition to bone density measurement is recommended in all patients with SLE in whom BMD measurement is indicated because of the existence of clinical risk factors for fractures. ${ }^{28}$

\section{BONE LOSS IN SLE \\ Epidemiology}

Osteopenia, defined as a T-score between -1.0 and -2.5 in the lumbar spine and/or the hip, is reported in 25$74 \%$ of patients with SLE, and osteoporosis, defined as a T-score less than -2.5 , in 1.4-68\% of patients with lupus in cohort studies. ${ }^{28}$ The wide variation in frequencies might be contributed to differences in study design and differences in size, age, sex, ethnic background, disease severity and medication use between the patient groups investigated.

Case-control studies have demonstrated a significantly increased prevalence of reduced bone mass in males ${ }^{29}$ and in females, ${ }^{30}$ with SLE as compared to age-matched healthy controls. For example, in a study on male patients with SLE from Hong Kong, 30\% of the patients had a reduced spine $\mathrm{BMD}$, defined as a $\mathrm{Z}$ score $<-2.0$, versus only $5 \%$ in healthy controls. At the femoral neck, these percentages were $10 \%$ and $0 \%$ in patients with SLE and healthy controls, respectively. ${ }^{29}$

\section{Relationship between BMD and fractures in SLE}

Although an increased prevalence of reduced BMD and an increased incidence of fractures have been demonstrated in patients with SLE, the relationship between BMD and fracture occurrence in patients with SLE is not yet fully clear. In contrast to cohort studies ${ }^{138}$ demonstrating reduced $\mathrm{BMD}$ as a risk factor for symptomatic fractures, and some studies reporting a significant association between low bone mass in the lumbar spine or the hip and the prevalence of morphometric vertebral fractures, ${ }^{19-21}$ other studies ${ }^{423}$ did not demonstrate a relationship between BMD and prevalent vertebral fractures. In addition, two studies demonstrated normal BMD in 29-35.8\% of the patients with SLE with one or more vertebral fractures. ${ }^{19} 20$ These discrepancies might be explained by several mechanisms of which the limitations of dual energy X-ray absorptiometry (DXA) measurement and the heterogeneity of patients with SLE are probably the most important ones. The occurrence of fractures in patients with normal bone mass illustrates the limited value of BMD measurement in the assessment of fracture risk in general, probably because DXA only measures the total amount of calcium/hydroxyapatite in a certain region. Therefore, the measurement can be influenced by atherosclerosis and spondyloarthritis. In addition, DXA does not measure connectivity of trabeculae and other aspects of bone quality. The occurrence of vertebral fractures in patients with normal BMD also points to the multifactorial aetiology of fractures in a complex disease as SLE. On top of the background fracture risk based on, among other factors, age, gender, postmenopausal status and ethnicity, the high frequency of treatment with GCs is supposed to be an important additional factor contributing to fracture risk in SLE. GC therapy has been associated with an increased fracture risk in individuals as compared to those who have similar BMD values and are not using GCs. ${ }^{31}$ In patients with SLE, three out of four population-based studies $^{2} 711$ showed that GC therapy is a significant and independent risk factor for fractures in patients with SLE. Unfortunately, none of the population-based studies on symptomatic fractures in SLE (table 2) investigated the relationship between BMD and fracture occurrence. 
In addition, an increased fall risk might also contribute to the increased fracture incidence in patients with SLE. No data on fall risk and the relationship with fracture occurrence in patients with SLE are currently available. However, a recent study ${ }^{32}$ demonstrated an association between reduced lower extremity muscle strength and physical disability in patients with SLE, a factor that might increase fall risk and subsequently influence fracture risk.

\section{Aetiology of bone loss in SLE}

The aetiology of the increased bone loss in SLE is supposed to be multifactorial and includes clinical osteoporosis risk factors, systemic inflammation, serological factors, metabolic factors, hormonal factors, medication-induced adverse effects and, possibly, genetic factors (figure 1). ${ }^{28}$

\section{Clinical osteoporosis risk factors}

In line with findings in the general population, age, ${ }^{1} 33$ postmenopausal status ${ }^{4} 33$ and low body weight ${ }^{1}$ or low body mass index ${ }^{1433}$ have been identified as independent risk factors for osteoporosis in patients with SLE.

The influence of gender on bone mass in SLE is not yet elucidated, since the far majority of studies investigated exclusively female patients. Only a few studies in male patients have been performed, one of which demonstrated reduced bone mass in male patients with SLE compared to healthy controls. ${ }^{29}$

Studies on the influence of ethnicity on bone mass in SLE show conflicting results. Similar to findings in the general population, two studies in patients with SLE demonstrated that white ethnicity ${ }^{34}$ or non-African Caribbean ethnicity ${ }^{3}$ was associated with osteoporosis. However, another study demonstrated significantly reduced BMD in African-American females with SLE as compared to white patients, after controlling for clinical variables and after adjustment for GC use. ${ }^{35}$ In the general population, smoking and excessive alcohol use are associated with an increased risk of osteoporosis. Alcohol use was associated with low bone mass in Chinese male patients with lupus in one study, ${ }^{29}$ but smoking has not been reported as an osteoporosis risk factor in several studies in SLE. ${ }^{3} 43$

\section{Role of systemic inflammation}

Chronic systemic inflammation is supposed to contribute to bone loss in SLE by both increasing osteoclastic bone resorption and by reducing osteoblastic bone formation. Studies in patients with SLE with active disease showed increased serum levels of tumour necrosis factor $(\mathrm{TNF})^{36}$ and increased levels of oxidised low-density lipoprotein (LDL) ${ }^{37}$ Oxidised lipids are able to activate $\mathrm{T}$ cells, which in turn can induce increased production of TNF and receptor activator of nuclear factor- $\mathrm{kB}$ (RANKL). Both TNF and RANKL increase the maturation and activity of osteoclasts. ${ }^{36}$ Moreover, oxidised LDL reduces osteoblast maturation, which in turn might negatively influence bone formation. ${ }^{38}$

A study on women with recently diagnosed and untreated SLE demonstrated decreased serum levels of osteocalcin, a marker for bone formation, and increased cross-links excretion in the urine, a marker for bone resorption, ${ }^{30}$ a finding that points to a change in bone

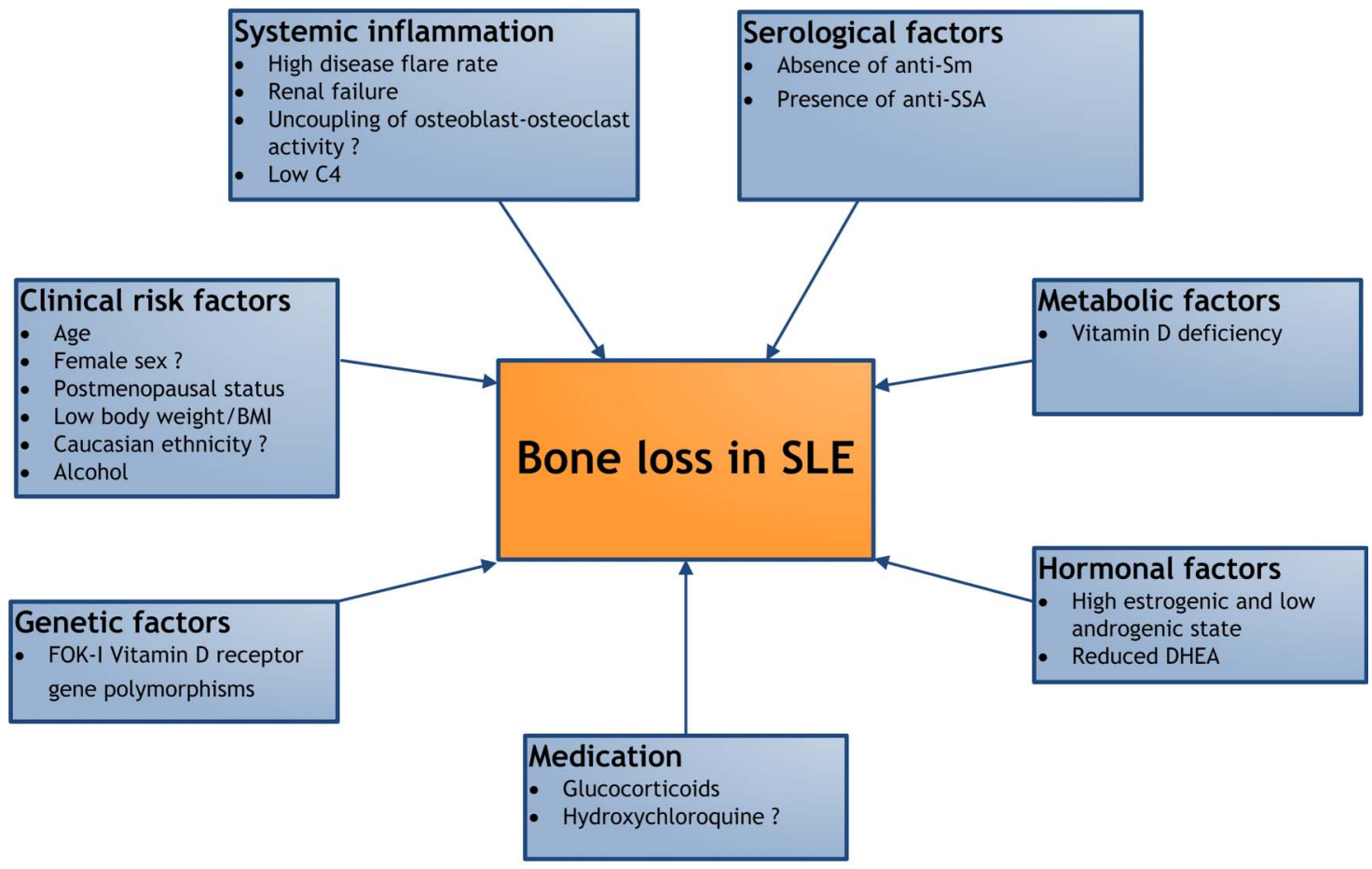

Figure 1 Factors contributing to bone loss in patients with systemic lupus erythematosus (SLE). BMI, body mass index; DHEA, dehydroepiandrosterone. 
metabolism due to the disease itself. In addition, low complement C4 levels, a marker of active disease, were associated with low spine BMD in the Hopkins Lupus Cohort. ${ }^{1}$

Cross-sectional studies failed to demonstrate a relationship between disease activity and bone mass in SLE. ${ }^{4} 1933{ }^{34}$ However, a recent 5-year prospective study on 125 Chinese women with SLE demonstrated an association between high disease flare rate and increased bone loss in spine and hip. ${ }^{39}$

Lupus nephritis occurs in up to $60 \%$ of patients with SLE during the disease course and may induce renal failure. ${ }^{40}$ In severe renal failure, secondary hyperparathyroidism, increased osteoclastic bone resorption and reduced 1,25-dihydroxyvitamin D serum levels may contribute to the development of osteoporosis. However, an association between impaired renal function and low bone mass has been demonstrated in only one study, ${ }^{33}$ which might be explained by the exclusion of patients with an impaired renal function from the majority of studies.

\section{Serological factors}

Data on the role of autoimmunity in bone resorption in SLE are very limited. In a cross-sectional study on 34 patients with SLE, an association between the presence of anti-Sm and higher hip bone mass was found, while the presence of anti-Ro was negatively associated with BMD in the hip. ${ }^{41}$ The relationship between absence of anti-Ro and higher bone mass may be explained by the fact that anti-Ro positive SLE patients are generally advised against sun exposure. ${ }^{41}$ In the same study, no relationship between the presence or absence of anti-dsDNA antibodies and BMD was found. The role of other autoantibodies with respect to bone resorption in SLE is currently unknown. A recent study has demonstrated that BMD is significantly reduced in healthy persons having antibodies against citrullinated protein (ACPA) as compared to ACPA negative individuals, a finding that is explained by the fact that ACPA directly induce bone loss by stimulating osteoclast differentation. ${ }^{42}$ Since the prevalence of ACPA positivity is much lower in patients with SLE compared to patients with rheumatoid arthritis, we suppose that ACPA might contribute to bone loss in the ACPA positive subgroup of patients with SLE, but, probably other mechanisms are playing a role.

\section{Metabolic factors}

Studies in different geographic regions have demonstrated an increased prevalence of vitamin D deficiency in patients with $\mathrm{SLE}^{43-45}$ a metabolic condition that may induce bone loss. A cross-sectional study on Dutch patients with SLE showed a significant association between low 25-hydroxyvitamin D $(25(\mathrm{OH}) \mathrm{D})$ serum levels and low BMD in the spine. ${ }^{4}$ In addition, a 6 -year follow-up study on 126 Dutch patients with lupus confirmed this finding: low $25(\mathrm{OH}) \mathrm{D}$ serum levels at baseline were significantly associated with bone loss in lumbar spine and hip. ${ }^{46}$
Vitamin D status in patients with SLE may be adversely affected by several factors: photosensitivity, use of sunscreens, dark skin pigment, renal failure, disease activity, GC therapy and, probably, hydroxychloroquine (HCQ) use.

Ultraviolet light intolerance is highly prevalent in patients with SLE, and leads to avoidance of sun exposure and subsequent reduced de novo vitamin D synthesis in the skin. Patients with dark skin pigment might be at increased risk for the development of vitamin D deficiency because melanin impairs vitamin $\mathrm{D}$ synthesis in the skin. A study in the USA indeed showed significantly lower vitamin D serum levels in African-American patients with SLE than in Caucasians. ${ }^{47}$ Patients with SLE are generally advised to use sunscreens continuously, which may induce decreased or even completely arrested vitamin $\mathrm{D}$ synthesis in the skin and subsequently reduced vitamin D levels. ${ }^{48}$

Renal failure may develop in patients with SLE due to chronic renal inflammation and/or hypertension, and may lead to reduced $1,25(\mathrm{OH})_{2}$ levels. A study on Canadian patients with lupus showed an association between high serum creatinine levels and low $1,25(\mathrm{OH})_{2}$ levels. ${ }^{45}$

Several cross-sectional studies have reported an inverse relationship between vitamin D insufficiency and SLE disease activity. However, a longitudinal study on 1006 patients with SLE from the Hopkins Lupus Cohort with a follow-up duration of 126 weeks showed a modest association between $25(\mathrm{OH}) \mathrm{D}$ serum levels and disease activity score. $^{49}$

GC therapy might adversely affect vitamin D levels. Chronic GC therapy has been demonstrated to alter vitamin $\mathrm{D}$ metabolism, leading to the formation of more biologically inactive metabolites, which results in decreased intestinal calcium transport. ${ }^{50}$ In patients with SLE, an association between cumulative GC exposure and low levels of both $25(\mathrm{OH}) \mathrm{D}$ and $1,25(\mathrm{OH})_{2}$ was demonstrated. ${ }^{45}$

The antimalarial, HCQ which is frequently used for the treatment of SLE, might impair vitamin D status in patients with lupus, since HCQ is supposed to inhibit the conversion of $25(\mathrm{OH}) \mathrm{D}$ in $1,25(\mathrm{OH})_{2}$ by inhibiting the enzyme hydroxylase $\alpha 1$. However, studies on the effect of HCQ on vitamin D levels in patients with SLE demonstrated conflicting results. ${ }^{34} 4351$

\section{Hormonal factors}

The hormonal status of patients with SLE has been described as a relatively high oestrogenic and low androgenic state, which is characterised by increased hydroxylation $\alpha 16$ of oestradiol, increased testosterone oxidation, and a reduction in dehydroepiandrosterone (DHEA). A study on premenopausal patients with SLE showed an association between low DHEA sulphate levels and low BMD ${ }^{52}$

\section{Role of medication}

GCs are extensively used for the treatment of lupus flares and complications of the disease. With respect to bone mass, GCs play a dual role: on the one hand, these drugs induce bone loss, but on the other hand, GCs also 
have a beneficial effect on bone mass by suppressing systemic inflammation. Several cross-sectional studies on the influence of GC use on bone mass in SLE have been performed and showed conflicting results. However, two of five small longitudinal studies ${ }^{53} 54$ and two recently performed larger prospective studies $^{39} 46$ demonstrated that bone loss occurs predominantly in patients with SLE treated with at least $7.5 \mathrm{mg}$ prednisone daily, while treatment with lower dose prednisone is not associated with bone loss (table 2). Thus, the use of high dose GCs in patients with more active disease might be associated with bone loss, while bone loss can be prevented in patients with mild disease treated with lower dosages of GCs.

The influence of HCQ use on bone mass in SLE is still unclear. Two cross-sectional studies in women with SLE reported higher BMD in the lumbar spine ${ }^{34} 41$ and at the hip, ${ }^{34}$ but a cross-sectional study on Chinese male patients with SLE showed significantly lower BMD in the spine and hip in patients who ever used HCQ as compared to never users. ${ }^{29}$ The 6 -year prospective study on Dutch patients with SLE revealed significant bone loss in the hip in patients taking $\mathrm{HCQ}^{46}$ In contrast, in the 5-year follow-up study on Chinese patients with lupus, no influence of HCQ use on bone mass was found. ${ }^{39}$ As a consequence of the high frequency of HCQ treatment in patients with lupus (since this drug is currently regarded as an 'anchor drug' for SLE therapy), further research on the influence of antimalarials on bone mass in SLE is needed. Importantly, if a possible adverse effect of HCQ on bone mass in SLE will be confirmed by future studies, this negative effect must be carefully weighed against the multiple beneficial effects of therapy with antimalarials in SLE. ${ }^{46}$

\section{Genetic factors}

Bone mass in SLE may be influenced by FOK-I vitamin D receptor (VDR) gene polymorphisms. A recent study on Dutch patients with SLE revealed that patients with SLE carrying the ff genotype of the FOK-I VDR have significantly higher mean BMD values in the lumbar spine than patients with the $\mathrm{FF}$ and Ff genotypes. ${ }^{55}$ This finding might be in part mediated by higher mean 25 $(\mathrm{OH}) \mathrm{D}$ serum levels in patients with the $\mathrm{ff}$ genotype, since a previous study showed increased 25(OH)D serum levels in patients with SLE carrying the FOK-I ff genotype compared to patients carrying the FF genotype ${ }^{56}$ However, FOK-I VDR gene polymorphisms were not associated with BMD at the hip, and mean BMD changes in lumbar spine and hip were not significantly different between the three genotypic groups during the 5.3 years of mean follow-up. ${ }^{55}$

\section{Fractures in SLE: conclusions}

Over the past decade, fractures have been recognised as an important disease complication in patients with SLE, and recent studies have provided more insight in the epidemiology, and the aetiology, of peripheral and vertebral fractures in SLE.
Population-based studies have demonstrated that patients with SLE have a 1.2-4.7-fold increased risk of symptomatic fractures as compared to age-matched and sex-matched controls, and previous GC use, longer disease duration and, probably, disease severity, have been identified as the most important risk factors. Cross-sectional studies in SLE populations of different ethnic background have shown a high prevalence (18$50 \%$ ) of vertebral fractures in these relatively young patients with mean ages ranging from 32 to 48 years. Importantly, one in three of these patients has normal bone density, which illustrates that the proportion of fractures attributable to low bone density is limited. In addition, the occurrence of vertebral fractures in patients with SLE with a BMD in the normal or osteopenic range points to impaired bone quality in patients with SLE, and emphasises that initiating antiosteoporotic treatment in these patients is warranted. The occurrence of vertebral fractures in patients with SLE with a BMD in the normal or osteopenic range also points to the importance of other factors contributing to fracture risk in SLE, such as GC use. Physicians should be aware that patients with SLE are very frequently treated with GCs, and GC therapy itself has been associated with an increased fracture risk, independent of bone mass. Therefore, the prescription of steroid-sparing agents is of great importance in case of inability to reduce GCs below doses acceptable for chronic use.

Future studies should also pay attention to fall risk in SLE. Fall risk in patients with SLE might be increased due to fatigue, arthritis, muscle weakness (due to inactivity and/or GC-induced myopathy and/or vitamin D deficiency), neuropathy or visual impairment. However, no data on fall risk and the relationship with fracture occurrence in patients with SLE are currently available.

Contributors IEMB drafted the article. WFL revised it critically for intellectual content. Both authors approved the final version to be published.

Competing interests None declared.

Provenance and peer review Commissioned; externally peer reviewed.

Data sharing statement No additional data are available.

Open Access This is an Open Access article distributed in accordance with the Creative Commons Attribution Non Commercial (CC BY-NC 4.0) license, which permits others to distribute, remix, adapt, build upon this work noncommercially, and license their derivative works on different terms, provided the original work is properly cited and the use is non-commercial. See: http:// creativecommons.org/licenses/by-nc/4.0/

\section{REFERENCES}

1. Petri M. Musculoskeletal complications of systemic lupus erythematosus in the Hopkins Lupus Cohort: an update. Arthritis Care Res 1995;8:137-45.

2. Ramsey-Goldman R, Dunn JE, Huang CF, et al. Frequency of fractures in women with systemic lupus erythematosus: comparison with United States population data. Arthritis Rheum 1999;42:882-90.

3. Yee CS, Crabtree N, Skan J, et al. Prevalence and predictors of fragility fractures in systemic lupus erythematosus. Ann Rheum Dis 2005;64:111-13.

4. Bultink IE, Lems WF, Kostense PJ, et al. Prevalence of and risk factors for low bone mineral density and vertebral fractures in patients with systemic lupus erythematosus. Arthritis Rheum 2005;54:2044-50. 
5. Lee C, Almagor O, Dunlop DD, et al. Self-reported fractures and associated factors in women with systemic lupus erythematosus. J Rheumatol 2007;34:2018-23.

6. Fangtham M, Petri M. Predictors of osteoporotic fracture in SLE [abstract]. Arthritis Rheum 2009;60(Suppl:S110).

7. Ekblom-Kullberg $\mathrm{S}$, Kautiainen $\mathrm{H}$, Alha $\mathrm{P}$, et al. Frequency of and risk factors for symptomatic bone fractures in patients with systemic lupus erythematosus. Scand J Rheumatol 2013;42:390-3.

8. Zhu TY, Griffith JF, Au SK, et al. Incidence of and risk factors for non-vertebral and vertebral fracture in female Chinese patients with systemic lupus erythematosus: a five-year cohort study. Lupus 2014;23:854-61.

9. Wang SH, Chang YS, Liu CJ, et al. Association of systemic lupus erythematosus with a higher risk of cervical but not trochanteric hip fracture: a nationwide population-based study. Arthritis Care Res (Hoboken) 2013;65:1674-81.

10. Rhew EY, Lee C, Eksarko P, et al. Homocysteine, bone mineral density, and fracture risk over 2 years of followup in women with and without systemic lupus erythematosus. J Rheumatol 2008;35:230-6.

11. Bultink IE, Harvey NC, Lalmohamed A, et al. Elevated risk of clinical fractures and associated risk factors in patients with systemic lupus erythematosus versus matched controls: a population-based study in the United Kingdom. Osteoporos Int 2014;25:1275-83.

12. Zonana-Nacach A, Barr SG, Magder LS, et al. Damage in systemic lupus erythematosus and its association with corticosteroids. Arthritis Rheum 2000;43:1801-8.

13. Weiss RJ, Wick MC, Ackermann PW, et al. Increased fracture risk in patients with rheumatic disorders and other inflammatory diseases. A case-control study with 53.108 patients with fracture. J Rheumatol 2010;37:2247-50.

14. Cooper C, Atkinson EJ, O'Fallon WM, et al. Incidence of clinically diagnosed vertebral fractures: a population-based study in Rochester, Minnesota, 1985-1989. J Bone Miner Res 1992;7:221-7.

15. Lems WF. Clinical relevance of vertebral fractures. Ann Rheum Dis 2007;66:2-4.

16. Oleksik A, Lips $P$, Dawson $A$, et al. Health-related quality of life in postmenopausal women with low BMD with or without prevalent vertebral fractures. J Bone Miner Res 2000;15:1384-92.

17. Hasserius R, Karlsson MK, Nilsson BE, et al. Prevalent vertebral deformities predict increased mortality and increased fracture rate in both men and women: a 10-year population-based study of 598 individuals from the Swedish cohort in the European Vertebral Osteoporosis study. Osteoporos Int 2003;14:61-8.

18. Borba VZ, Matos PG, da Silva Viana PR, et al. High prevalence of vertebral deformity in premenopausal systemic lupus erythematosus patients. Lupus 2005;14:529-33.

19. Mendoza-Pinto C, García-Carrasco M, Sandoval-Cruz H, et al. Risk factors of vertebral fractures in women with systemic lupus erythematosus. Clin Rheumatol 2009;28:579-85.

20. Li EK, Tam LS, Griffith JF, et al. High prevalence of asymptomatic vertebral fractures in Chinese women with systemic lupus erythematosus. J Rheumatol 2009;36:1646-52.

21. Almehed K, Hetényi S, Ohlsson $\mathrm{C}$, et al. Prevalence and risk factors of vertebral compression fractures in female SLE patients. Arthritis Res Ther 2010;12:R153.

22. García-Carrasco M, Mendoza-Pinto C, Riebeling C, et al. Influence of prevalent vertebral fractures on the quality of life in patients with systemic lupus erythematosus. Isr Med Assoc J 2011;13:333-7.

23. Furukawa M, Kiyohara C, Horiuchi T, et al. Prevalence and risk factors of vertebral fracture in female Japanese patients with systemic lupus erythematosus. Mod Rheumatol 2013;23:765-73.

24. Genant HK, Wu CY, van Kuijk C, et al. Vertebral fracture assessment using a semiquantitative technique. J Bone Miner Res 1993;8:1137-48.

25. Jacobs J, Tsang A Sjoe MW, et al. Unexpected severe incident vertebral fractures in patients with systemic lupus erythematosus: comment on the article by Zhu et al. Lupus 2015;24:222-3.

26. Siris ES, Adler R, Bilezikian J, et al. The clinical diagnosis of osteoporosis: a position statement from the National Bone Health Alliance Working Group. Osteoporos Int 2014;25:1439-43.

27. NOGG Guideline for diagnosis and management of osteoporosis in postmenopausal women and men from the age of 50 years in the UK. http://www.shef.ac.uk/NOGG Updated March 2014.

28. Bultink IE. Osteoporosis and fractures in systemic lupus erythematosus. Arthritis Care Res (Hoboken) 2012;64:2-8.

29. Mok CC, Ying SK, To $\mathrm{CH}$, et al. Bone mineral density and body composition in men with systemic lupus erythematosus: a case control study. Bone 2008;43:327-31.

30. Teichmann J, Lange U, Stracke $\mathrm{H}$, et al. Bone metabolism and bone mineral density of systemic lupus erythematosus at the time of diagnosis. Rheumatol Int 1999;18:137-40.
31. Van Staa TP, Laan RF, Barton IP, et al. Bone density threshold and other predictors of vertebral fracture in patients receiving oral glucocorticoid therapy. Arthritis Rheum 2003;48:3224-9.

32. Andrews JS, Trupin L, Schmajuk G, et al. Muscle strength, muscle mass, and physical disability in women with systemic lupus erythematosus. Arthritis Care Res (Hoboken) 2015;67:120-7.

33. Almehed K, Forsblad d'Elia H, Kvist G, et al. Prevalence and risk factors of osteoporosis in female SLE patients: extended report. Rheumatology (Oxford) 2007;46:1185-90.

34. Lakshminarayanan S, Walsh S, Mohanraj M, et al. Factors associated with low bone mineral density in female patients with systemic lupus erythematosus. J Rheumatol 2001;28:102-8.

35. Lee C, Almagor O, Dunlop DD, et al. Association between African American race/ethnicity and low bone mineral density in women with systemic lupus erythematosus. Arthritis Rheum 2007;57:585-92.

36. Svenungsson E, Fei GZ, Jensen-Urstad K, et al. TNF- $\alpha$ : a link between hypertriglyceridaemia and inflammation in SLE patients with cardiovascular disease. Lupus 2003;12:454-61.

37. Frostegard J, Svenungsson E, Wu R, et al. Lipid peroxidation is enhanced in patients with systemic lupus erythematosus and is associated with arterial and renal disease manifestations. Arthritis Rheum 2005;52:192-200.

38. Moerman EJ, Teng K, Lipschitz DA, et al. Aging activates adipogenic and suppresses osteogenic programs in mesenchymal marrow stroma/stem cells: the role of PPAR- $\gamma 2$ transcription factor and TGF- $\beta$ /BMP signaling pathways. Aging Cell 2004;3:379-89.

39. Zhu TY, Griffith JF, Au SK, et al. Bone mineral density change in systemic lupus erythematosus: a 5-year followup study. J Rheumatol 2014;41:1990-7.

40. Cameron JS. Lupus nephritis. J Am Soc Nephrol 1999;10:413-24.

41. Mok CC, Mak A, Ma KM. Bone mineral density in postmenopausal Chinese patients with systemic lupus erythematosus. Lupus 2005;14:106-12.

42. Kleyer A, Finzel S, Rech J, et al. Bone loss before the clinical onset of rheumatoid arthritis in subjects with anticitrullinated protein antibodies. Ann Rheum Dis 2014;73:854-60.

43. Huisman AM, White KP, Algra A, et al. Vitamin D levels in women with systemic lupus erythematosus and fibromyalgia. J Rheumatol 2001;28:2535-9.

44. Borba VZ, Vieira JG, Kasamatsu T, et al. Vitamin D deficiency in patients with active systemic lupus erythematosus. Osteoporos Int 2009;20:427-33.

45. Toloza SM, Cole DE, Gladman DD, et al. Vitamin D insufficiency in a large female SLE cohort. Lupus 2010;19:13-19.

46. Jacobs J, Korswagen LA, Schilder AM, et al. Six year follow-up study of bone mineral density in patients with systemic lupus erythematosus. Osteoporos Int 2013;24:1827-33.

47. Kamen DL, Cooper GS, Bouali $\mathrm{H}$, et al. Vitamin D deficiency in systemic lupus erythematosus. Autoimmun Rev 2006;5:114-17.

48. Matsuoka LY, Wortsman J, Hanifan N, et al. Chronic sunscreen use decreases circulating concentrations of 25-hydroxyvitamin D: a preliminary study. Arch Dermatol 1988;124:1802-4.

49. Petri M, Bello KJ, Fang $\mathrm{H}$, et al. Vitamin $\mathrm{D}$ in systemic lupus erythematosus. Modest association with disease activity and the urine protein-to-creatine ratio. Arthritis Rheum 2013;65:1865-71.

50. Klein RG, Arnaud SB, Gallagher JC, et al. Intestinal calcium absorption in exogenous hypercortisonism. Role of 25-hydroxyvitamin D and corticosteroid dose. J Clin Invest 1977;60:253-9.

51. Ruiz-Irastorza G, Egurbide MV, Olivares N, et al. Vitamin D deficiency in systemic lupus erythematosus: prevalence, predictors and clinical consequences. Rheumatology 2008;47:920-3.

52. Formiga F, Moga I, Nolla JM, et al. The association of dehydroepiandrosterone sulphate levels with bone mineral density in systemic lupus enythematosus. Clin Exp Rheumatol 1997;15:387-92.

53. Kipen Y, Briganti E, Strauss B, et al. Three year followup of bone mineral density change in premenopausal women with systemic lupus erythematosus. J Rheumatol 1999;26:310-17.

54. Jardinet D, Lefebvre C, Depresseux G, et al. Longitudinal analysis of bone mineral density in pre-menopausal female systemic lupus erythematosus patients: deleterious role of glucocorticoid therapy at the lumbar spine. Rheumatology (Oxford) 2000;39:389-92.

55. Jacobs J, Korswagen LA, Cohen Tervaert JW, et al. The association between FOK-I vitamin D receptor gene polymorphisms and bone mineral density in patients with systemic lupus erythematosus [abstract]. Ann Rheum Dis 2014;73:533-4.

56. Monticielo OA, Brenol JC, Chies JA, et al. The role of Bsml and Fokl vitamin $D$ receptor gene polymorphisms and serum 25-hydroxyvitamin D in Brazilian patients with systemic lupus erythematosus. Lupus 2012;21:43-52. 